\title{
Pharmacological treatment for patients with coronavirus disease 2019: systematic review of randomized controlled trials
}

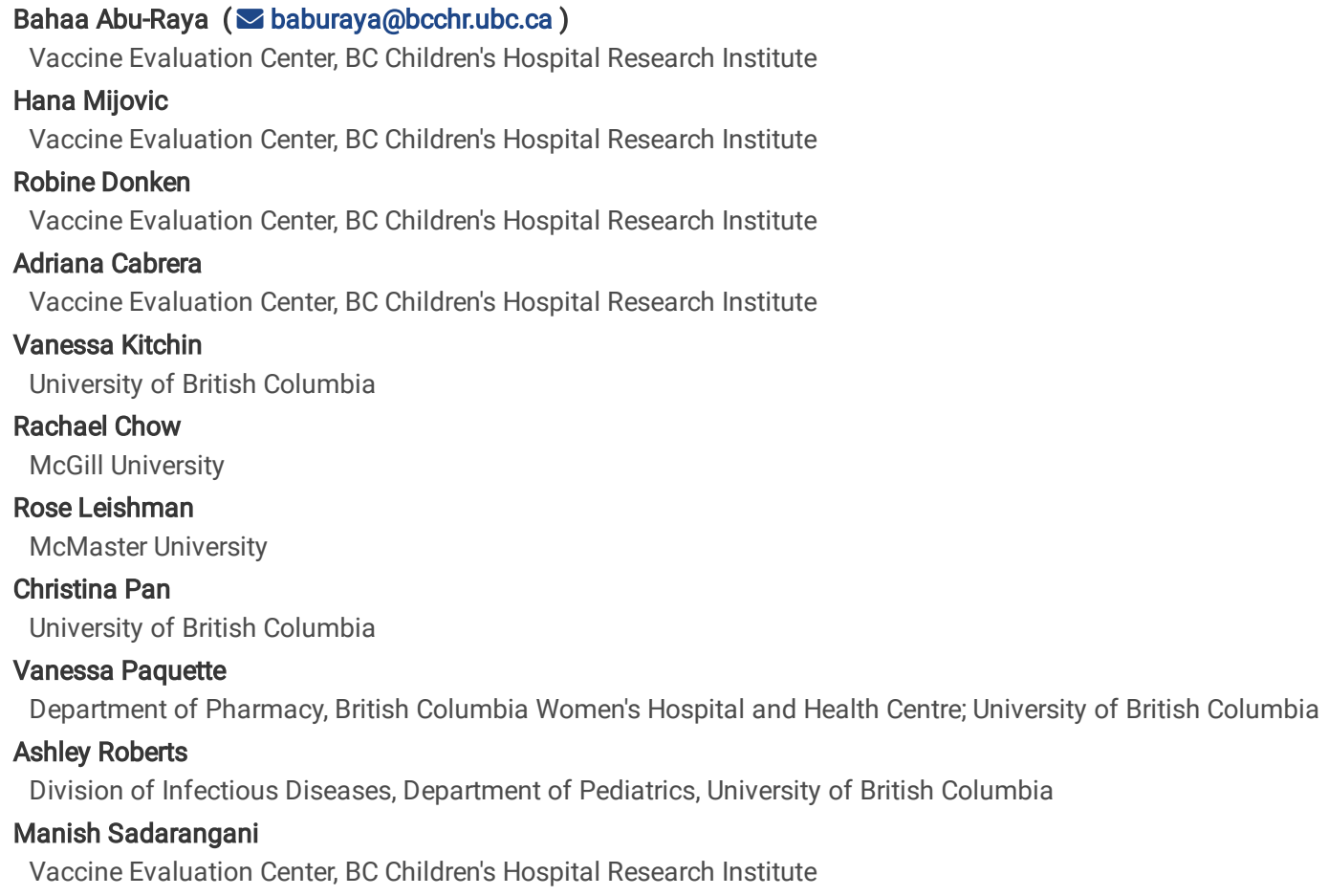




\section{Abstract}

Background: The best treatment for COVID-19 is not known, with numerous agents under investigation. We determined the outcomes of patients with COVID19 treated with different pharmacological agents.

Methods: In this systematic review, we searched Ovid MEDLINE, EMBASE, CINAHL, and Cochrane Central Register of Controlled Trials for studies published between $1^{\text {st }}$ January and $12^{\text {th }}$ August, 2020 . We included randomized controlled trials (RCTs) of patients with COVID-19 treated with any pharmacological agent and compared with a different pharmacological agent, placebo or standard of care.

Results: From 6346 citations, 19 studies were included, with an overall low risk of bias. Two RCTs evaluated the use of remdesivir in laboratory-confirmed moderate-to-severe COVID-19. One study found that 10 days of remdesivir was associated with shortened recovery time. Neither found reduction in mortality. One RCT found no association of lopinavir/ritonavir with time to clinical improvement, or mortality benefit. Two RCTs of hydrochloroquine in patients with mild, early disease demonstrated no reduction in disease severity, hospitalization rate, death or viral load. Two RCTs observed no association of hydrochloroquine in hospitalized patients with mild-to-moderate disease with virological clearance, improvement in symptoms, need for respiratory support or death. One RCT showed that the use of steroids was associated with improved survival in patients with moderate-to-severe disease, especially those requiring respiratory support.

Conclusions: There is evidence for the benefit of steroids in patients with moderate-to-severe disease. Remdesivir might shorten recovery time in patients hospitalized with moderate-to-severe disease. There is currently no evidence to support the use of lopinavir/ritonavir or hydrochloroquine.

Study's Registration: PROSPERO CRD42020184433.

\section{Background}

Coronavirus disease 2019 (COVID-19) is a rapidly spreading and fatal pandemic caused by severe acute respiratory syndrome coronavirus 2 (SARS-CoV-2). Disease symptoms can range from mild-to-moderate influenza-like symptoms to severe acute respiratory disease syndrome (ARDS) necessitating admission to the intensive care unit (ICU) for ventilator and hemodynamic support, and leading to fatalities which are more prevalent in adults and older individuals with comorbidities (1-3). While mild-to-moderate COVID-19 is a self-resolving disease, pharmacological treatment might be indicated in more severe cases, and includes drugs that target either key steps of the virus life cycle or the host immune response to SARS-CoV-2. Given the current lack of evidence to support the use of most drugs, the use of COVID-19 pharmacological therapies is recommended mainly in the setting of clinical trials (4).

An observational study did not demonstrate benefit of lopinavir/ritonavir (1). Some other antiviral (remdesivir (5)) and immunomodulatory agents (e.g. hydrochloroquine [HCQ] and azithromycin(6)) have shown favorable results in non-randomized studies. However, these studies should be interpreted carefully due to limitations in study design. We aimed to review the outcomes of patients with COVID-19 treated with different pharmacological treatments in randomized controlled trials (RCTs).

\section{Methods}

\section{Search strategy and selection criteria}

In this systematic review, we used a methodologically rigorous approach (Cochrane Handbook of Systematic Reviews) including stringent formulation of the research question and development of the protocol; double-blind screening and selection of the literature; data extraction; and collation, and report of the results.We developed a search strategy and refined its parameters in consultation with a research librarian (member of our research team). We searched Ovid MEDLINE, EMBASE, CINAHL, and the Cochrane Central Register of Controlled Trials databases for published studies in English exploring the benefit of different pharmacological agents on outcome in patients with COVID-19, published between $1^{\text {st }}$ January and $12^{\text {th }}$ August, 2020 following PRISMA guidelines (7) (Ovid MEDLINE search criteria in Supplementary method). We included randomized studies of patients with COVID-19 treated with a specific pharmacological agent and a control group treated with a different pharmacological agent, placebo or standard of care (SOC) only, in which outcomes (clinical, radiological, and/or virological) were reported. We excluded studies that did not contain a control group, non-human studies, non-randomized studies, cluster-randomized studies and studies in which no outcomes were reported. Letters, editorials and review articles containing no primary data were excluded. Inclusion and exclusion criteria were specified in advance and documented in the study protocol. References were screened by title and abstract by two authors, with disagreements resolved in a group discussion. Articles screened and found to be possibly eligible were fully assessed against inclusion and exclusion criteria by two authors, with controversies resolved by group discussion.

\section{Data extraction}

Data were extracted from articles that met the inclusion criteria independently by two authors and included the following: study settings, cohort characteristics, treatments investigated and main results. Disagreements between authors were resolved by discussion including a third author.

\section{Risk of bias assessment}

Risk of bias (ROB) of included RCTs was assessed against the Cochrane ROB tool for RCTs. The study was registered at PROSPERO International prospective register of systematic reviews (CRD42020184433).

Role of the funding source: There was no specific funding source for this study. 


\section{Results}

Overall, 6346 references were screened for eligibility. Of these, 39 full-text articles were assessed against inclusion and exclusion criteria. Nineteen articles met the inclusion criteria and were included in the systematic review and qualitative synthesis (Supplementary Figure 1). Thirteen out of 19 studies included patients with moderate-to-severe disease, and 16 studies enrolled hospitalized patients. Most of the studies were deemed to have low risk of bias (Supplementary Tables 1-3).

Two RCTs assessed the effect of remdesivir on hospitalized patients with laboratory-confirmed moderate-to-severe COVID-19. While a small study from China $(n=237)$ did not find difference in time to clinical improvement between remdesivir and placebo during 28 days follow up, a larger multi-country study $(n=1059)$ reported that 10 days of remdesivir was associated with shortened time to recovery (11 vs. 15 days) during 28 days follow up. Neither study found reduction in mortality at day 14 after enrollment (Table 1). ROB was low/unclear in some domains (Supplementary Table 1).

A study investigating lopinavir/ritonavir in patients with laboratory-confirmed COVID-19 did not meet the primary outcome of the study of time to clinical improvement, evaluated at day 28, and also did not show reduction in mortality (Table 1). ROB was low (Supplementary Table 1). Studies of combination regimens of lopinavir/ritonavir with other antivirals and other immunomodulators were also included. In patients receiving lopinavir/ritonavir combined with novaferon, compared with novaferon alone, the percentage of patients with negative SARS-CoV-2 PCR was higher at day 3 and 6 after randomization, and the median time until negative SARS-CoV-2 PCR was shorter (Table 1). In another study, the combination of lopinavir/ritonavir with IFN b-1b and ribavirin (RBV) was associated with shorter time until negative SARS-CoV-2 PCR, shorter time to resolution of symptoms and decreased hospital length of stay (LOS), compared with lopinavir/ritonavir alone. ROB was low in both studies (Supplementary Table 1).

Four RCTs investigated HCQ use in hospitalized and clinic patients. Two of these RCTs reported that early treatment of outpatients with mild disease (4-5 days after symptoms onset) did not reduce disease severity, hospitalization rate, death or SARS-CoV-2 viral load (Table 1). ROB was variable in these studies (Supplementary Table 1). Two other RCTs found no difference in virological clearance during 28 days follow up after HCQ administration in hospitalized patients with mild-to-moderate disease. HCQ administration was also not associated with difference in symptoms, need for respiratory support or death (Table 1). ROB was low for most domains in these two studies (Supplementary Table 1).

Two published RCTs that assessed the effect of administration of steroids on 28-day mortality were identified. The first was an interim analysis of the RECOVERY trial that found that administration of dexamethasone resulted in a lower case-fatality rate compared with standard of care. Subgroup analyses indicated that the finding was prominent among patients receiving invasive mechanical ventilation, but not observed in patients not receiving respiratory support at randomization. A study in Brazil with a lower number of patients randomized, reported that methylprednisolone did not result in a reduction in 7day, 14-day or 28-day case-fatality rate compared with placebo (Table 2). The two studies had low ROB (Supplementary Table 2).

Four RCTs that evaluated immunomodulators (other than steroids) as single agents in treating COVID-19 patients were identified (Table 3). The rate of hospitalization was not different in outpatients treated with febuxostat compared with HCQ. Receipt of IFN b-1a did not result in improvement in time to clinical response, although mortality benefit was noted, especially if administered within 10 days of symptoms onset. In a small study, colchicine was associated with improved time to clinical deterioration. Ruxolitinib receipt did not result in reduction in time to clinical improvement or mortality benefit. Overall, the studies were found to have low ROB (Supplementary Table 3).

\section{Discussion}

There is an urgent need to establish the optimal pharmacological treatment of patients with COVID-19. In this systematic review, we aimed to assess the effect of different pharmacological treatments on outcomes in patients with COVID-19. Remdesivir was found to be associated with shortened time to clinical improvement in patients hospitalized with moderate-severe disease. In addition, an improved survival rate was noted for steroids administered to patients, especially those who required mechanical ventilation and/or supplemental oxygen at diagnosis. Lopinavir/ritonavir was not associated with clinical improvement and did not demonstrate mortality benefit. HCQ administered to outpatients or inpatients did not reduce the severity of disease or hospitalization rates, enhance virological clearance, improve symptoms, reduce need for respiratory support or prevent death.

Remdesivir is an inhibitor of the viral RNA polymerase and has been shown to have inhibitory activity against SARS-CoV-2, SARS-CoV-1 and MERS-CoV in vitro (8-12). While a small study did not find that remdesivir administration was associated with shortening of time to clinical improvement (13), a multi-country study found that a 10 days course of Remdesivir was associated with shortening of time to recovery (14). However, current evidence from both studies did not support that there is reduction in mortality at day 14 after randomization. It should be noted that the former study did not complete full enrollment (due to the end of outbreak in China) of the target number of patients, and thus had a lower sample size that might have precluded any definite conclusion. In addition, the modest clinical benefit observed (14) with a highly expensive drug might challenge its use in some settings (e.g. low-middle income countries). Experience 
with other human coronaviruses is limited. In non-human primate studies, remdesivir reduced MERS-CoV lung virus levels and lung damage when initiated 12 hours after inoculation with the virus $(15,16)$.

Lopinavir is a protease inhibitor, and is combined with ritonavir to increase lopinavir's plasma half-life through the inhibition of cytochrome P450. This combination is an established agent in the treatment of HIV. Lopinavir has in vitro inhibitory activity against SARS-CoV-1 (17, 18), the causative agent of SARS disease. Lopinavir also has activity against MERS-CoV observed in vitro (19) and in an animal model (20). The addition of RBV to lopinavir/ritonavir reduced the risk of ARDS or death, as well SARS-CoV-1 viral load among patients with SARS (21). The combination of lopinavir/ritonavir, RBV and IFN a has been associated with survival in case reports of patients with MERS (22-24). In this systematic review, one RCT did not find lopinavir/ritonavir to be associated with shorter time to clinical improvement, or have mortality benefit in patients with SARS-CoV-2 (25). One RCT found that the combination of IFN b-1b, lopinavir/ritonavir, and RBV was associated with shorter time to negative SARS-CoV-2 PCR, shorter time to resolution of symptoms and decreased hospital LOS, compared with lopinavir/ritonavir alone (26). This might have practical implications related to isolation precautions for patients. In addition, reduction of hospital LOS might enable health service to cope with higher load of patients, provide better care in severe disease, and might also reduce costs of hospitalization.

Chloroquine and its hydroxyl analogue HCQ are well known as antimalarial drugs. Both drugs have been shown to block the viral replication of SARS-CoV-2 in cell cultures, suggesting that they might have potent antiviral activity against SARS-CoV-2 in vivo (12, 27). In our systematic review, two RCTs performed on outpatients found no reduced disease severity or hospitalization rates after treatment with HCQ early in the course of mild disease (28, 29). Two RCTS on the use of HCQ in hospitalized patients also failed to demonstrate that HCQ administration for patients with mild-moderate disease enhanced virological clearance, improved symptoms, reduced need for respiratory support or prevented death $(30,31)$.

One of two published studies showed that dexamethasone treatment was associated with reduction in 28-day mortality, especially among patients who required invasive mechanical ventilation or supplemental oxygen (32). While this finding was not supported by a recent study from Brazil, which also recruited patients with moderate to severe COVID-19, differences in the results might stem from the lower number of patients, the later presentation after symptoms onset and the higher baseline mortality rate without steroids in the latter compared with the former study (33). A recent prospective meta-analysis of RCTs that evaluated the efficacy of corticosteroids in critically ill patients found that corticosteroid administration was associated with a reduction in 28-day mortality when compared with SOC or placebo (odds ratio $0.66,95 \% \mathrm{Cl}$ : $0.53-0.82$ ) (34). Thus, The World Health Organization (WHO) is currently considering amending their COVID treatment guidelines to recommend the use of steroids in the treatment of critically ill patients. Limited data from earlier SARS outbreaks were not conclusive regarding the benefit of steroids (35). Systematic review of the use of corticosteroids in patients with MERS did not suggest a reduction in mortality, and was associated with delayed MERS-CoV RNA clearance (36).

Investigation of other immunomodulatory agents as a single agent has shown less promising results, and published articles were limited by small number of

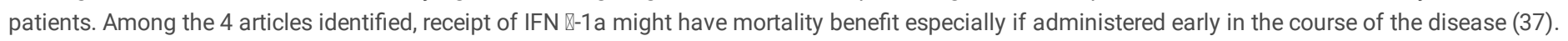
However, the high costs of these drugs might preclude their use, especially in low-middle income countries settings. IFN b was found to be the most potent inhibitor of SARS-CoV among other IFNs (38). However, a retrospective study showed that RBV plus recombinant IFN (rIFN- $\alpha 2 a$, rIFN- $a 2 b$, or rIFN- $\beta 1 a)$ did not result in a reduction in 90-day mortality amongst patients with severe MERS-CoV infection (38).

\section{Conclusions}

Remdesivir is associated with shortening time to clinical improvement in patients hospitalized with moderate-severe disease, and its use should be supported by future research. Currently, there is no evidence to support the use of HCQ in either outpatients with mild disease or inpatients with mild-moderate disease, nor the use of lopinavir/ritonavir in hospitalized patients. Our systematic review supports the use of steroids in critically ill patients.

There is a need to investigate the role of pharmacological treatment in adults with some underlying comorbidities (e.g. human immunodeficiency virus infection) or other specific populations (e.g. pediatric population, pregnant women) who have up to now largely been excluded from RCTs. In addition, there is a need to further explore the role of steroids in the treatment of moderate-severe COVID-19 as well as the optimal dose and duration of corticosteroid therapy in critically ill cases. Meta-analysis of effects of different pharmacological treatments may be possible as additional RCTs are published.

\section{List Of Abbreviations}

COVID-19: Coronavirus disease 2019

SARS-CoV-2: severe acute respiratory syndrome coronavirus 2

ARDS: acute respiratory disease syndrome 
ICU: intensive care unit

HCQ: hydrochloroquine

RCTs: randomized controlled trials

SOC: standard of care

ROB: Risk of bias

RBV: ribavirin

LOS: length of stay

\section{Declarations}

Ethics approval and consent to participate: Not applicable.

Consent for publication: Not applicable.

Availability of data and material: Not applicable.

Competing interests: BA, VK, HM, AC, RL, CP, RC declare no competing interests. MS has been an investigator on projects funded by GlaxoSmithKline, Merck, Pfizer, Sanofi-Pasteur, Seqirus, Symvivo and VBI Vaccines. All funds have been paid to his institute, and he has not received any personal payments.

Acknowledgement: BA is supported by the Canadian Health and Research Institute Vanier Canada Graduate scholarship. HM is supported through the University of British Columbia Clinician Investigator Program. RD is supported by the Canadian Immunization Research Network Trainee Scholarship and the Michael Smith Foundation for Health Research Trainee Award. MS is supported via salary awards from the BC Children's Hospital Foundation, the Canadian Child Health Clinician Scientist Program and the Michael Smith Foundation for Health Research.

Funding: This study did not receive any specific funding.

Authors' contributions: All authors conceived and designed the systematic review. BA, VK, HM, AC, RL, CP, RC searched the scientific literature. BA, HM, AC, RL, $\mathrm{CP}, \mathrm{RC}, \mathrm{RD}$ drafted the tables. BA wrote the first draft of the manuscript. All authors critically reviewed and edited the manuscript. All authors reviewed and approved the final version of the manuscript.

Acknowledgements: Not applicable.

\section{Tables}

Table 1: Summary of findings table of randomized controlled trials of anti-infective agents for treatment of COVID-19 


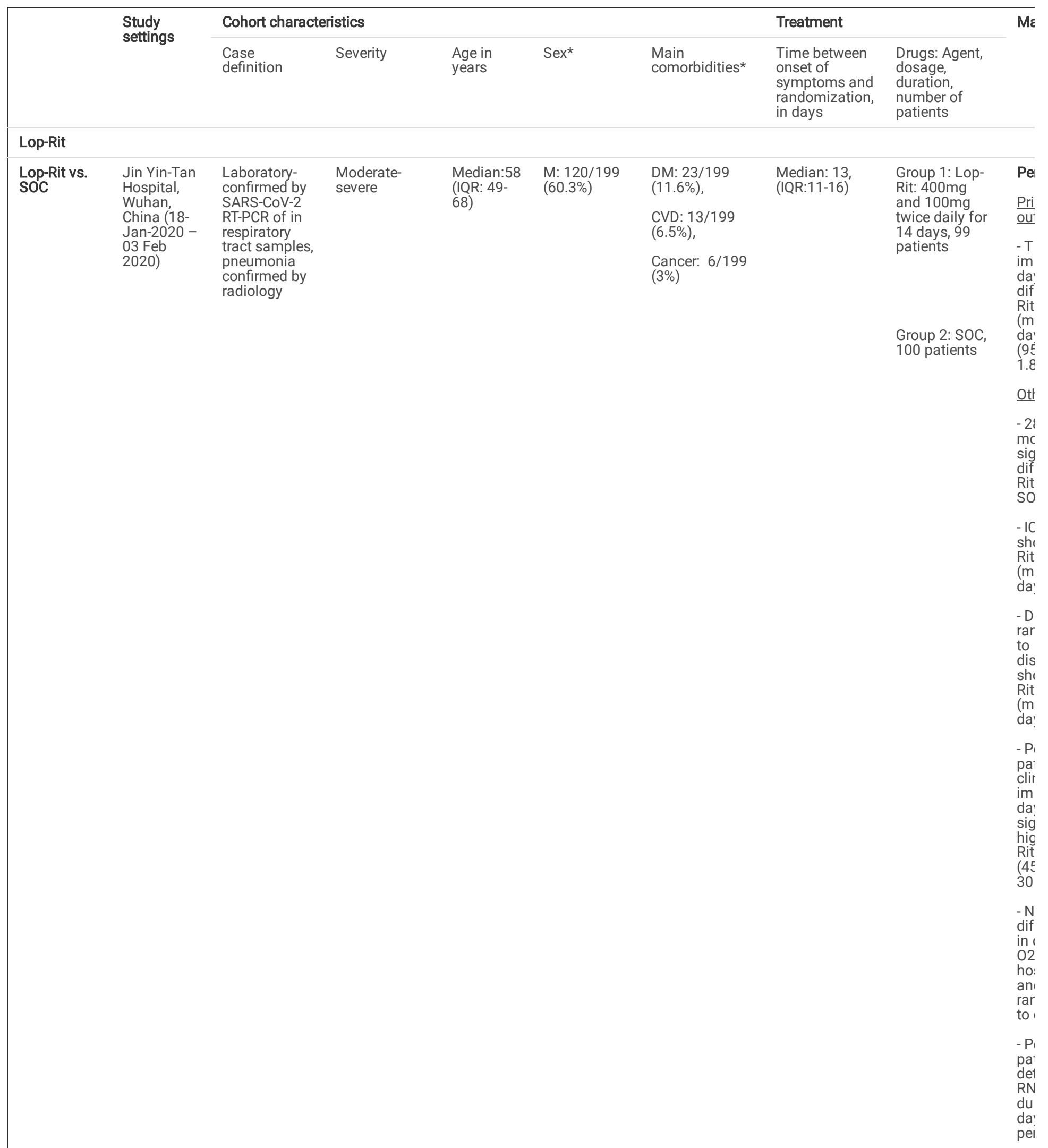

Rem

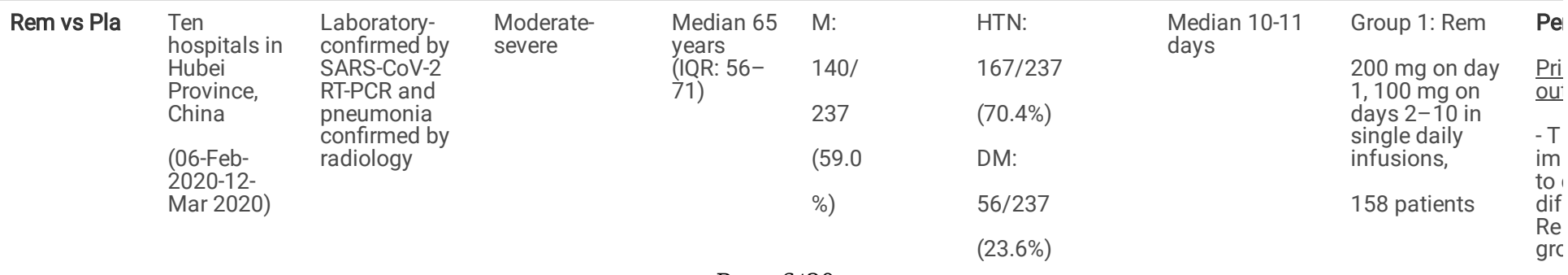


CHD:

Group 2: Pla, 21

$17 / 237$

(7.1\%)

79 patients $\quad 0 \cdot \varepsilon$

(allowed Pro

steroids)

\section{(1)}

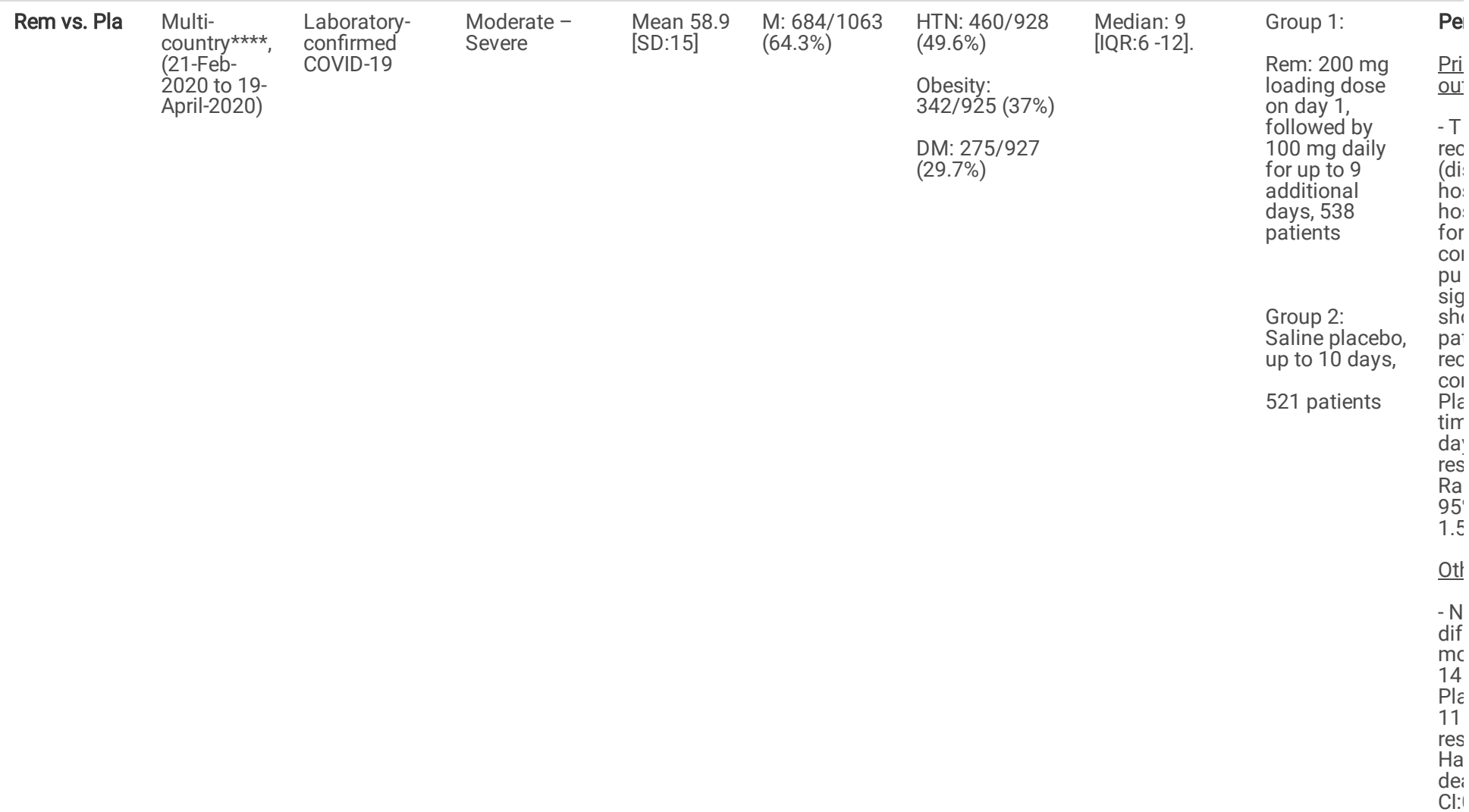

HCQ

\begin{tabular}{|c|c|c|c|c|c|c|c|c|c|}
\hline \multicolumn{10}{|c|}{ Hospitalized } \\
\hline $\begin{array}{l}\text { HCQ plus } \\
\text { SOC vs. }\end{array}$ & $\begin{array}{l}\text { Multi- } \\
\text { center, } 3\end{array}$ & $\begin{array}{l}\text { Laboratory } \\
\text { confirmed }\end{array}$ & $\begin{array}{l}\text { Mild-Moderate } \\
\text { disease }\end{array}$ & $\begin{array}{l}\text { Mean: } 46 \\
\text { (SD:14.7) }\end{array}$ & $\begin{array}{l}\text { M: 82/150 } \\
(55 \%)\end{array}$ & $\begin{array}{l}\text { DM: } 21 / 150 \\
(14 \%)\end{array}$ & $\begin{array}{l}\text { Mean } 16.6(S D \\
10.5)\end{array}$ & Group 1: HCQ & $\mathrm{Pe}$ \\
\hline
\end{tabular}




\begin{tabular}{|c|c|c|c|c|c|c|}
\hline $\begin{array}{l}\text { HCQ vs. } \\
\text { HCQ and } \\
\text { AZM vs. } \\
\text { SOC }\end{array}$ & $\begin{array}{l}\text { Multicenter, } \\
\text { Brazil, (29 } \\
\text { Mar 20 - } \\
\text { 02 Jun 20) }\end{array}$ & $\begin{array}{l}\text { Suspected or } \\
\text { laboratory } \\
\text { confirmed } \\
\text { COVID-19 by } \\
\text { SARS-CoV-2 } \\
\text { RT-PCR }\end{array}$ & $\begin{array}{l}\text { Mild to } \\
\text { moderate } \\
\text { hospitalized }\end{array}$ & $\begin{array}{l}\text { Mean: } \\
50.3 \\
\text { (SD:14.6) }\end{array}$ & $\begin{array}{l}\text { M: } 388 / 665 \\
(58.3 \%)\end{array}$ & $\begin{array}{l}\text { HTN: 258, } \\
(38.8 \%)\end{array}$ \\
\hline & & . & & & & $\begin{array}{l}127 / 665 \\
(19.1 \%)\end{array}$ \\
\hline
\end{tabular}

75 patients
OB:

37/665 (16.3\%)
Pr

Group 1:

Mc dose $2 x$ daily $\quad$ Ou

(7 days), 221

patients

Group 2: HCQ:

400mg dose $2 x$ daily (7 days) and AZM 500mg dose $1 \mathrm{x}$ daily (7 days), 217 patients

Group 3: SOC, 227 patients $-\mathrm{N}$
dif clir 15 of orc 1 i $-\mathrm{N}$ $-\mathrm{N}$ bet
dif the the sce sel 


\section{Outpatient}

\begin{tabular}{|c|c|c|c|c|c|c|}
\hline HCQ vs. Pla & $\begin{array}{l}\text { Multi-site, } \\
\text { United } \\
\text { States and } \\
\text { Canada } \\
\text { (22-March- } \\
2020 \text { to 20- } \\
\text { May-2020) }\end{array}$ & $\begin{array}{l}\text { Laboratory- } \\
\text { confirmed by } \\
\text { SARS-CoV-2 } \\
\text { RT-PCR or } \\
\text { COVID-19- } \\
\text { compatible } \\
\text { symptoms } \\
\text { with } \\
\text { epidemiologic } \\
\text { link }\end{array}$ & $\begin{array}{l}\text { Mild } \\
\text {,outpatients (4 } \\
\text { or fewer days } \\
\text { of symptoms) }\end{array}$ & $\begin{array}{l}\text { Median } 40 \\
\text { [IQR: 32- } \\
50]\end{array}$ & $\begin{array}{l}\text { M: } \\
185 / 423 \\
(44 \%)\end{array}$ & $\begin{array}{l}\text { Asthma: } \\
\text { 48/423 (11\%), } \\
\text { HTN: 46/423, } \\
\text { 11\%), } \\
\text { DM:15/423 } \\
(4 \%),\end{array}$ \\
\hline
\end{tabular}

$\begin{array}{ll}236 / 423(56 \%) & \text { Group 1: HCQ } \\ \text { of participants } & 800 \text { mg once, } \\ \text { enrolled within } & \text { followed } \\ \begin{array}{ll}1 \text { day of } \\ \text { symptom }\end{array} & \text { by } 600 \mathrm{mg} \text { in } 6 \\ \text { onset } & \text { to } 8 \text { hours, } \\ & \text { then } 600 \mathrm{mg} \\ & \text { daily for } 4 \\ & \text { more days), } \\ & 212 \text { patients }\end{array}$

$\underline{\mathrm{Pe}}$

Pri

ou

- N

rec

link

212 patients

Group 2: Pla

(folic acid 400

$\mathrm{mcg}$, in

Canada

lactose), 211

patients 


\section{Other treatments}

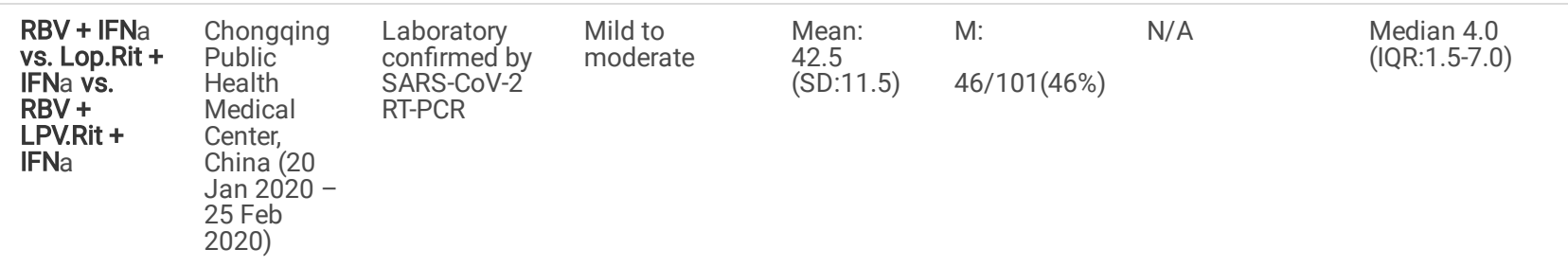


Group 2: Lop

$400 \mathrm{mg}$ and

Rit $100 \mathrm{mg}$ )

every $12 \mathrm{~h}$ for

14 days, 41

patients

$\begin{array}{lll}\text { Six } & \text { Laboratory } & \text { Moderate } \\ \text { hospitals, } & \text { confirmed } & \\ \text { Russia, Apr- } & \text { COVID-19 } & \\ \text { May 2020 } & \text { pneumonia } & \end{array}$

Favipiravir M $30 / 60$

$1600 / 600$

mg: mean

51.0

(50\%)

(15.6)

(5)

$\geq 60$ years $\quad \mathrm{N} / \mathrm{A}$
and/or chronic
diseases:

28/60 (46.7\%)

Favipiravir

1800/800

mg: mean

52.6 (15)

SOC:

mean 48.6

(16.1)

$\begin{array}{ll}\text { Group 1: } & \text { Pe } \\ \text { Favipiravir } & \\ \text { 1600 mg BID } & \text { Pri } \\ \text { day 1, 600 mg } & \text { ou } \\ \text { BID days 2-14, } & \text { - V } \\ \text { 20 patients } & \text { by } \\ & \text { sig } \\ \text { Group 2: } & \text { dif } \\ \text { Favipiravir } & \text { Fa } \\ \text { 1800 mg BID } & \text { SO } \\ \text { day 1, 800 mg } & \text { (92 } \\ \text { BID days 2-14, } & \text { 16 } \\ \text { 20 patients } & \\ \text { (10\% received } & \\ \text { steroids) } & \text { Ot } \\ \text { Group 3: SoC, } & \text { ou } \\ \text { 20 patients } & -\mathrm{V} \\ \text { (75\% received } & \text { on } \\ \text { HCQ or CQ, 5\% } & \text { sig } \\ \text { Lop/Rit, } & \text { hic } \\ \text { 10\% steroids } & \text { Fa } \\ & \text { SO } \\ & \text { 30 }\end{array}$

$\mathrm{Pe}$

$\underline{\mathrm{Pri}}$

- V

by

dif

Sa'

(92

16

Oth

ou

- V

sig
hiç
Fa'

SO

$-\mathrm{M}$

bo

ten

no

37

sig

$\mathrm{Fa}$

SO

da'

$-\mathrm{N}$

dif

bet

fal

so

im

chi

on

Ch

on 


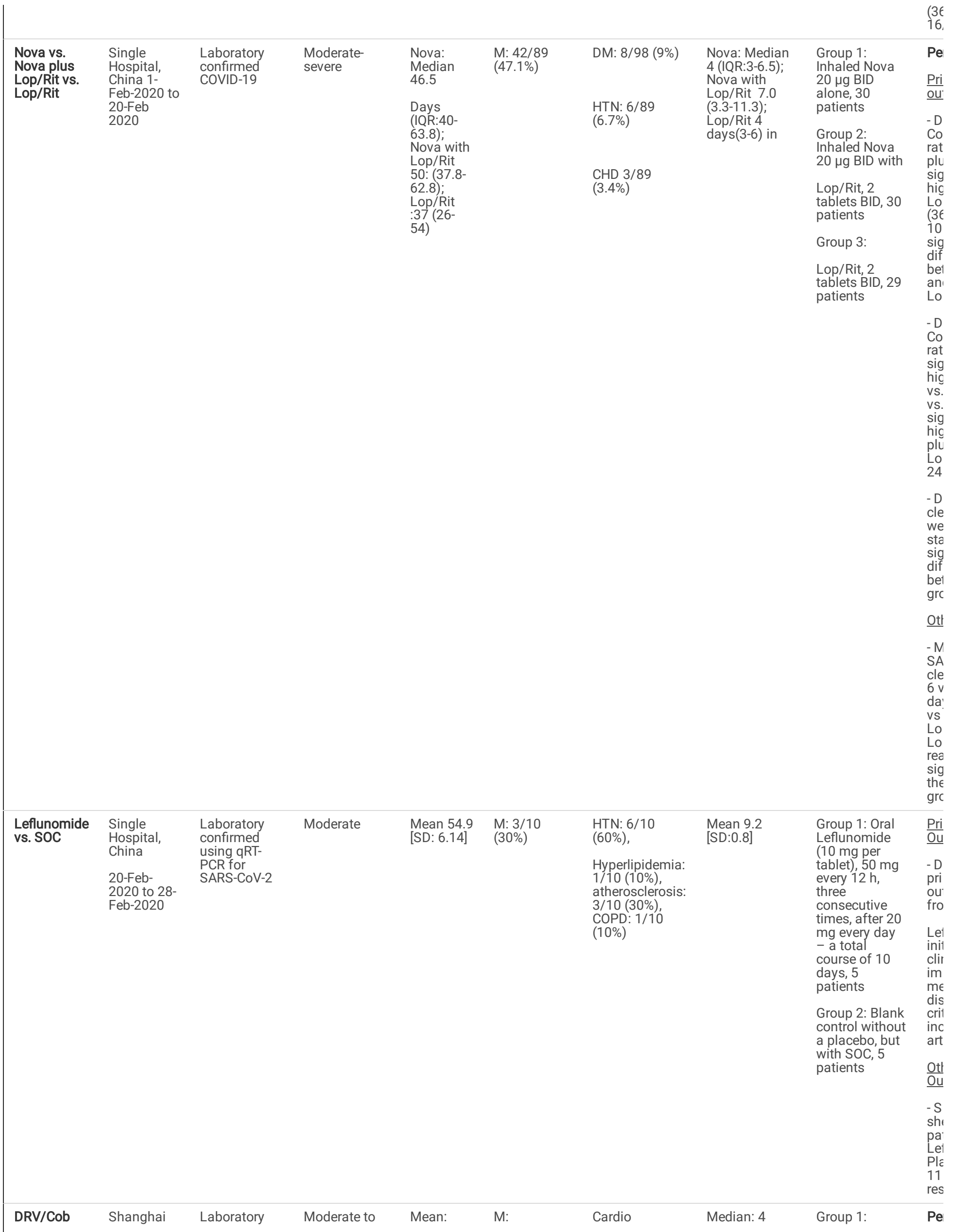




\begin{tabular}{|c|c|c|c|c|c|c|c|c|}
\hline vs. SOC & $\begin{array}{l}\text { Public } \\
\text { Health } \\
\text { Clinical } \\
\text { Center, } \\
\text { China, } 30 \\
\text { Jan 2020 - } \\
06 \text { Feb } \\
\text { 2020) }\end{array}$ & $\begin{array}{l}\text { confirmed } \\
\text { using SARS- } \\
\text { CoV-2 RT- } \\
\text { PCT }\end{array}$ & Severe. & $\begin{array}{l}47.2 \text { (SD: } \\
2.8)\end{array}$ & $18 / 30(60 \%)$ & $\begin{array}{l}\text { Vascular } \\
\text { disease: } 8 / 30 \\
\text { (26.7\%) } \\
\text { DM: } \\
2 / 30(6.7 \%)\end{array}$ & (IQR: 2-5) & $\begin{array}{l}\text { DRV/Cob: } \\
1 \text { pill (800mg } \\
\text { DRV, 150mg } \\
\text { Cob) 1x daily } \\
\text { (5 days), } \\
15 \text { Patients } \\
\text { Group 2: } \\
\text { SoC, no oral } \\
\text { antiviral drugs, } \\
15 \text { Patients } \\
\text { All received } \\
\text { IFNa-2b + Soc } \\
\text { per guidelines } \\
\text { from China }\end{array}$ \\
\hline
\end{tabular}

Abbreviations: Ref: reference; Lop-Rit: Lopinavir-ritonavir; RT-PCR: reverse-transcriptase-polymerase- chain-reaction; NA: not available; SOC: standard of care; IQR: interquartile range; M: male; DM: Diabetes mellitus; ITT: intention to treat; LOS: length of stay; O2: oxygen; HTN: Hypertension; CHD: Coronary Heart Disease; Rem: Remdesivir; Pla: placebo; CQ: Chloroquine Diphosphate; CKD: Chronic kidney disease; OR: Odds ratio; IFN: interferon; SOFA: Sequential organ failure assessment; Nova: Novaferon; CVD: Cerebrovascular disease; IMV: invasive mechanical ventilation; N/A: not available; HR: Hazard ratio; HD: Heart Disease; CVD: cardio vascular disease; RD: respiratory disease; AZM: Azithromycin; OB: obesity; RBV: Ribavirin, LPV: Lopinavir, URT: Upper respiratory tract; COPD: Chronic obstructive pulmonary disease; DRV/c: Darunavir/cobiscistat, URT: upper respiratory tract; Cob: Cobicistat. * Number out of total and \% **

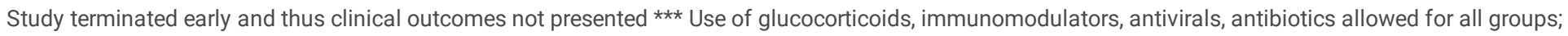

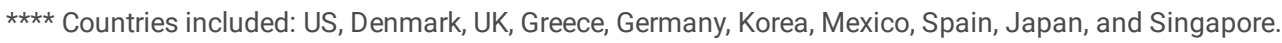

Table 2: Summary of findings table of randomized controlled trials of steroid treatment for COVID-19 


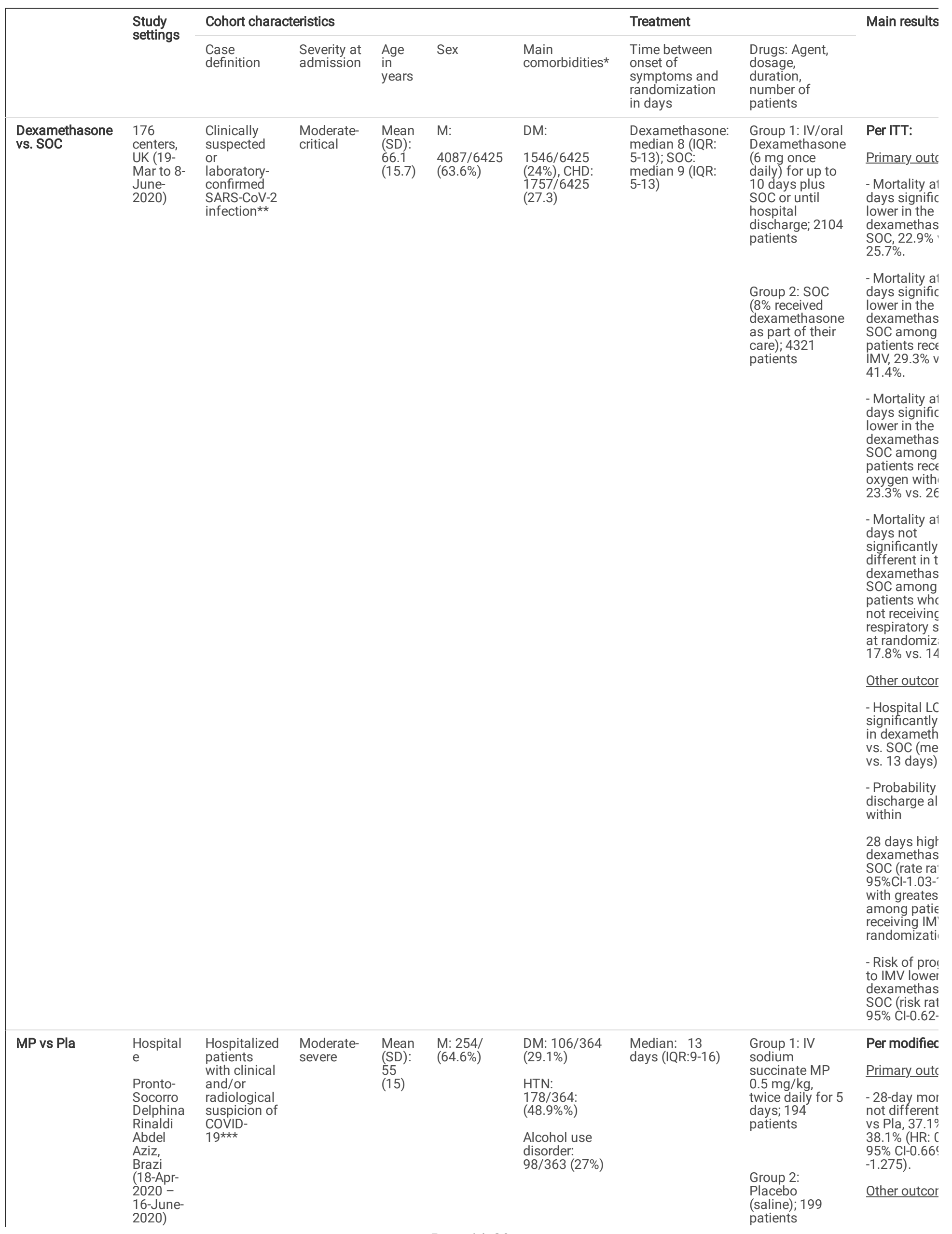


- 7-day and mortality no different in $\mathrm{A}$ Pla.

- Presence RNA in naso/oroph swab on das 7 not differe MP vs Pla

- Need for IN day 7 or Hos LOS not diff

MP vs. Pla.

- Reduced $2 \varepsilon$ mortality in I group in pos analysis incl patients $>60$

Abbreviation: COVID-19: Coronavirus disease 19; Ref: reference; SD: Standard deviation; IQR: interquartile range; NA: not available; SOC: standard of care; M: male; DM: Diabetes mellitus; ITT: intention to treat; LOS: length of stay; O2: oxygen; HTN: Hypertension; CHD: Coronary Heart Disease; Pla: placebo; MP: Methylprednisolone; IV: Intravenous; IMV: invasive mechanical ventilation.

* Number out of total and \%; ** $88 \%$ confirmed in dexamethasone and $89 \%$ in SOC group; *** $83 \%$ of MP and $79 \%$ of Pla were laboratory confirmed by SARSCoV-2 RT-PCR

Table 3: Summary of findings table of randomized controlled trials of immunomodulatory treatment for COVID-19 


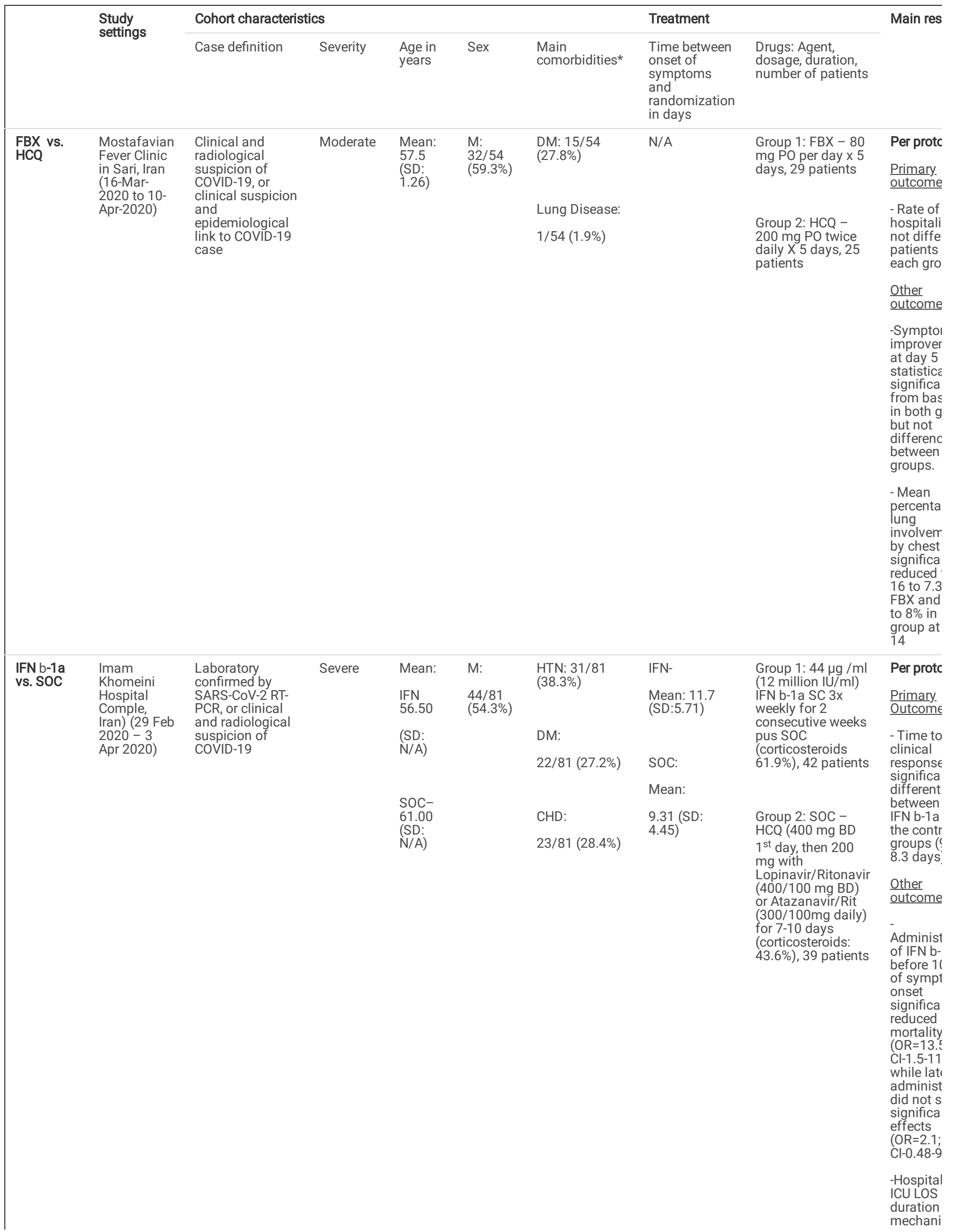


- Receipt

IFN b-1a

indepenc

factor fo

survival

benefit a

days in

multivari

analysis,

after

adjustme

IVIG and

corticost

receipt.

\begin{tabular}{|c|c|c|c|}
\hline $\begin{array}{l}\text { Colchicine } \\
\text { vs. SOC }\end{array}$ & $\begin{array}{l}16 \text { tertiary } \\
\text { care } \\
\text { hospitals, } \\
\text { Greece (03- } \\
\text { April- } 2020 \\
\text { - } 27 \text { April } \\
2020)\end{array}$ & $\begin{array}{l}\text { Laboratory- } \\
\text { confirmed by } \\
\text { SARS-CoV-2 RT- } \\
\text { PCR }\end{array}$ & $\begin{array}{l}\text { Moderate- } \\
\text { severe }\end{array}$ \\
\hline
\end{tabular}

Median: $\quad$ M:

(IQR:54- (58.1\%)

76)
HTN:

N/A

DM: 21/105

(20\%)

Dyslipidemia:

33/105

(31.4\%), CAD

$(14 / 105,13.3 \%)$
Group 1:

Colchicine $(1.5 \mathrm{mg}$

loading dose

followed by $0.5 \mathrm{mg}$

and maintenance

of $0.5 \mathrm{mg}$ twice

daily) for 3 weeks

or until hospital

discharge, 55

patients

Group 2: SOC **, 50 patients.

\section{Per ITT}

Primary

outcome

- Deterior

by 2 poir

a 7-gradt

scale, wi

weeks or

discharg

higher in

SOC vs. 1

Colchicir

group (1.

$1.8 \%)$

$(\mathrm{OR}=0.11$

Cl: 0.01-

0.096).

Other

outcome

- No

significa differenc hospital between Colchicir SOC (me 12 vs. 13 days).

\begin{tabular}{|c|c|c|c|c|c|c|c|}
\hline $\begin{array}{l}\text { Ruxolitinib } \\
\text { vs. Pla }\end{array}$ & $\begin{array}{l}\text { Three } \\
\text { hospitals, } \\
\text { China (9- } \\
\text { Feb-2020 - } \\
\text { 28-Feb- } \\
\text { 2020) }\end{array}$ & $\begin{array}{l}\text { Clinically } \\
\text { suspected, } \\
\text { epidemiologically } \\
\text { linked or } \\
\text { laboratory } \\
\text { confirmed cases }\end{array}$ & Severe & $\begin{array}{l}\text { Median: } \\
63 \\
\text { (IQR:58- } \\
68)\end{array}$ & $\begin{array}{l}\text { M: } 24 \\
/ 41 \\
(58.5 \%)\end{array}$ & $\begin{array}{l}\text { HTN: } 16 / 41 \\
\text { (39.0\%), DM: } \\
\text { 8/41 (19.5), } \\
\text { Coronary artery } \\
\text { heart disease } \\
3 / 41(7.3 \%)\end{array}$ & $\begin{array}{l}\text { Median: } 20 \\
\text { (IQR: 17-28) }\end{array}$ \\
\hline
\end{tabular}

\section{Group 1: \\ Ruxolitinib $5 \mathrm{mg}$ twice a day with SOC, 20 patients) \\ Group 2: Placebo $(100 \mathrm{mg}$ Vitamin C) twice a day with SOC, 21 patients}

SOC included: antiviral therapy, corticosteroid
Modified

Primary outcome

- No

significa differenc time to $\mathrm{C}$ improver in Ruxoli vs. Pla g (median 15 days) (Hazard 1.669; 9 ? $0.836-$ 3.335)

- Signific higher percenta patients showed significa improver of follow CT at da' in Ruxoli vs. Pla,

(90\% vs. $61.9 \%)$.

Other outcome 


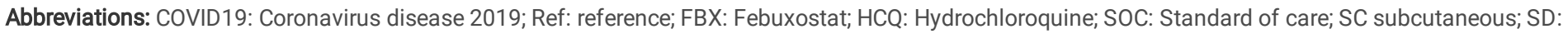

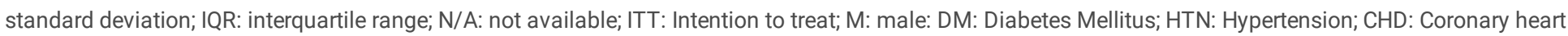

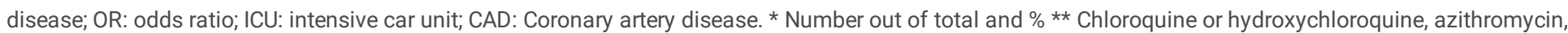
lopinavir or ritonavir, tocilizumab.

\section{References}

1. Zhou F, Yu T, Du R, Fan G, Liu Y, Liu Z, et al. Clinical course and risk factors for mortality of adult inpatients with COVID-19 in Wuhan, China: a retrospective cohort study. Lancet. 2020.

2. Guan WJ, Ni ZY, Hu Y, Liang WH, Ou CQ, He JX, et al. Clinical Characteristics of Coronavirus Disease 2019 in China. N Engl J Med. 2020.

3. Grasselli G, Zangrillo A, Zanella A, Antonelli M, Cabrini L, Castelli A, et al. Baseline Characteristics and Outcomes of 1591 Patients Infected With SARSCoV-2 Admitted to ICUs of the Lombardy Region, Italy. JAMA. 2020.

4. Infectious Diseases Society of America . Infectious Diseases Society of America Guidelines on the Treatment and Management of Patients with COVID-19 Infection. Available online: https://www.idsociety.org/COVID19guidelines .

5. Grein J, Ohmagari N, Shin D, Diaz G, Asperges E, Castagna A, et al. Compassionate Use of Remdesivir for Patients with Severe Covid-19. N Engl J Med. 2020.

6. Gautret P, Lagier JC, Parola P, Hoang VT, Meddeb L, Mailhe M, et al. Hydroxychloroquine and azithromycin as a treatment of COVID-19: results of an openlabel non-randomized clinical trial. Int J Antimicrob Agents. 2020:105949.

7. Liberati A, Altman DG, Tetzlaff J, Mulrow C, Gøtzsche PC, loannidis JP, et al. The PRISMA statement for reporting systematic reviews and meta-analyses of studies that evaluate healthcare interventions: explanation and elaboration. BMJ. 2009;339:b2700.

8. Sheahan TP, Sims AC, Leist SR, Schäfer A, Won J, Brown AJ, et al. Comparative therapeutic efficacy of remdesivir and combination lopinavir, ritonavir, and interferon beta against MERS-CoV. Nat Commun. 2020;11(1):222.

9. Agostini ML, Andres EL, Sims AC, Graham RL, Sheahan TP, Lu X, et al. Coronavirus Susceptibility to the Antiviral Remdesivir (GS-5734) Is Mediated by the Viral Polymerase and the Proofreading Exoribonuclease. mBio. 2018;9(2).

10. Brown AJ, Won JJ, Graham RL, Dinnon KH, Sims AC, Feng JY, et al. Broad spectrum antiviral remdesivir inhibits human endemic and zoonotic deltacoronaviruses with a highly divergent RNA dependent RNA polymerase. Antiviral Res. 2019;169:104541.

11. Sheahan TP, Sims AC, Graham RL, Menachery VD, Gralinski LE, Case JB, et al. Broad-spectrum antiviral GS-5734 inhibits both epidemic and zoonotic coronaviruses. Sci Transl Med. 2017;9(396).

12. Wang M, Cao R, Zhang L, Yang X, Liu J, Xu M, et al. Remdesivir and chloroquine effectively inhibit the recently emerged novel coronavirus (2019-nCoV) in vitro. Cell Res. 2020;30(3):269-71.

13. Wang Y, Zhang D, Du G, Du R, Zhao J, Jin Y, et al. Remdesivir in adults with severe COVID-19: a randomised, double-blind, placebo-controlled, multicentre trial. Lancet. 2020;395(10236):1569-78.

14. Beigel JH, Tomashek KM, Dodd LE, Mehta AK, Zingman BS, Kalil AC, et al. Remdesivir for the Treatment of Covid-19 - Preliminary Report. N Engl J Med. 2020. 
15. de Wit E, Rasmussen AL, Falzarano D, Bushmaker T, Feldmann F, Brining DL, et al. Middle East respiratory syndrome coronavirus (MERS-CoV) causes transient lower respiratory tract infection in rhesus macaques. Proc Natl Acad Sci U S A. 2013;110(41):16598-603.

16. de Wit E, Feldmann F, Cronin J, Jordan R, Okumura A, Thomas T, et al. Prophylactic and therapeutic remdesivir (GS-5734) treatment in the rhesus macaque model of MERS-CoV infection. Proc Natl Acad Sci U S A. 2020;117(12):6771-6.

17. Chen F, Chan KH, Jiang Y, Kao RY, Lu HT, Fan KW, et al. In vitro susceptibility of 10 clinical isolates of SARS coronavirus to selected antiviral compounds. J Clin Virol. 2004;31(1):69-75.

18. Wu CY, Jan JT, Ma SH, Kuo CJ, Juan HF, Cheng YS, et al. Small molecules targeting severe acute respiratory syndrome human coronavirus. Proc Natl Acad Sci U S A. 2004;101(27):10012-7.

19. de Wilde AH, Jochmans D, Posthuma CC, Zevenhoven-Dobbe JC, van Nieuwkoop S, Bestebroer TM, et al. Screening of an FDA-approved compound library identifies four small-molecule inhibitors of Middle East respiratory syndrome coronavirus replication in cell culture. Antimicrob Agents Chemother. 2014;58(8):4875-84.

20. Chan JF, Yao Y, Yeung ML, Deng W, Bao L, Jia L, et al. Treatment With Lopinavir/Ritonavir or Interferon- $\beta 1$ b Improves Outcome of MERS-CoV Infection in a Nonhuman Primate Model of Common Marmoset. J Infect Dis. 2015;212(12):1904-13.

21. Chu CM, Cheng VC, Hung IF, Wong MM, Chan KH, Chan KS, et al. Role of lopinavir/ritonavir in the treatment of SARS: initial virological and clinical findings. Thorax. 2004;59(3):252-6.

22. Kim UJ, Won EJ, Kee SJ, Jung SI, Jang HC. Combination therapy with lopinavir/ritonavir, ribavirin and interferon-a for Middle East respiratory syndrome. Antivir Ther. 2016;21(5):455-9.

23. Spanakis N, Tsiodras S, Haagmans BL, Raj VS, Pontikis K, Koutsoukou A, et al. Virological and serological analysis of a recent Middle East respiratory syndrome coronavirus infection case on a triple combination antiviral regimen. Int J Antimicrob Agents. 2014;44(6):528-32.

24. Min CK, Cheon S, Ha NY, Sohn KM, Kim Y, Aigerim A, et al. Comparative and kinetic analysis of viral shedding and immunological responses in MERS patients representing a broad spectrum of disease severity. Sci Rep. 2016;6:25359.

25. Cao B, Wang Y, Wen D, Liu W, Wang J, Fan G, et al. A Trial of Lopinavir-Ritonavir in Adults Hospitalized with Severe Covid-19. N Engl J Med. 2020.

26. Hung IF, Lung KC, Tso EY, Liu R, Chung TW, Chu MY, et al. Triple combination of interferon beta-1b, lopinavir-ritonavir, and ribavirin in the treatment of patients admitted to hospital with COVID-19: an open-label, randomised, phase 2 trial. Lancet. 2020;395(10238):1695-704.

27. Yao X, Ye F, Zhang M, Cui C, Huang B, Niu P, et al. In Vitro Antiviral Activity and Projection of Optimized Dosing Design of Hydroxychloroquine for the Treatment of Severe Acute Respiratory Syndrome Coronavirus 2 (SARS-CoV-2). Clin Infect Dis. 2020.

28. Skipper CP, Pastick KA, Engen NW, Bangdiwala AS, Abassi M, Lofgren SM, et al. Hydroxychloroquine in Nonhospitalized Adults With Early COVID-19: A Randomized Trial. Ann Intern Med. 2020.

29. Mitjà $\mathrm{O}$, Corbacho-Monné M, Ubals M, Tebe C, Peñafiel J, Tobias A, et al. Hydroxychloroquine for Early Treatment of Adults with Mild Covid-19: A Randomized-Controlled Trial. Clin Infect Dis. 2020.

30. Tang W, Cao Z, Han M, Wang Z, Chen J, Sun W, et al. Hydroxychloroquine in patients with mainly mild to moderate coronavirus disease 2019: open label, randomised controlled trial. BMJ. 2020;369:m1849.

31. Cavalcanti AB, Zampieri FG, Rosa RG, Azevedo LCP, Veiga VC, Avezum A, et al. Hydroxychloroquine with or without Azithromycin in Mild-to-Moderate Covid-19. N Engl J Med. 2020.

32. Horby P, Lim WS, Emberson JR, Mafham M, Bell JL, Linsell L, et al. Dexamethasone in Hospitalized Patients with Covid-19 - Preliminary Report. N Engl J Med. 2020.

33. Jeronimo CMP, Farias MEL, Val FFA, Sampaio VS, Alexandre MAA, Melo GC, et al. Methylprednisolone as Adjunctive Therapy for Patients Hospitalized With COVID-19 (Metcovid): A Randomised, Double-Blind, Phase Ilb, Placebo-Controlled Trial. Clin Infect Dis. 2020.

34. Sterne JAC, Murthy S, Diaz JV, Slutsky AS, Villar J, Angus DC, et al. Association Between Administration of Systemic Corticosteroids and Mortality Among Critically III Patients With COVID-19: A Meta-analysis. JAMA. 2020.

35. Stockman LJ, Bellamy R, Garner P. SARS: systematic review of treatment effects. PLoS Med. 2006;3(9):e343.

36. Arabi YM, Mandourah Y, Al-Hameed F, Sindi AA, Almekhlafi GA, Hussein MA, et al. Corticosteroid Therapy for Critically III Patients with Middle East Respiratory Syndrome. Am J Respir Crit Care Med. 2018;197(6):757-67.

37. Davoudi-Monfared E, Rahmani H, Khalili H, Hajiabdolbaghi M, Salehi M, Abbasian L, et al. A Randomized Clinical Trial of the Efficacy and Safety of Interferon $\beta-1 \mathrm{a}$ in Treatment of Severe COVID-19. Antimicrob Agents Chemother. 2020;64(9).

38. Arabi YM, Shalhoub S, Mandourah Y, Al-Hameed F, Al-Omari A, Al Qasim E, et al. Ribavirin and Interferon Therapy for Critically III Patients With Middle East Respiratory Syndrome: A Multicenter Observational Study. Clin Infect Dis. 2020;70(9):1837-44.

39. Huang YQ, Tang SQ, Xu XL, Zeng YM, He XQ, Li Y, et al. No Statistically Apparent Difference in Antiviral Effectiveness Observed Among Ribavirin Plus Interferon-Alpha, Lopinavir/Ritonavir Plus Interferon-Alpha, and Ribavirin Plus Lopinavir/Ritonavir Plus Interferon-Alpha in Patients With Mild to Moderate Coronavirus Disease 2019: Results of a Randomized, Open-Labeled Prospective Study. Front Pharmacol. 2020;11:1071.

40. Ivashchenko AA, Dmitriev KA, Vostokova NV, Azarova VN, Blinow AA, Egorova AN, et al. AVIFAVIR for Treatment of Patients with Moderate COVID-19: Interim Results of a Phase II/III Multicenter Randomized Clinical Trial. Clin Infect Dis. 2020.

41. Zheng F, Zhou Y, Zhou Z, Ye F, Huang B, Huang Y, et al. SARS-CoV-2 clearance in COVID-19 patients with Novaferon treatment: A randomized, open-label, parallel-group trial. Int J Infect Dis. 2020;99:84-91.

42. Hu K, Wang M, Zhao Y, Zhang Y, Wang T, Zheng Z, et al. A Small-Scale Medication of Leflunomide as a Treatment of COVID-19 in an Open-Label BlankControlled Clinical Trial. Virol Sin. 2020.

Page $19 / 20$ 
43. Chen J, Xia L, Liu L, Xu Q, Ling Y, Huang D, et al. Antiviral Activity and Safety of Darunavir/Cobicistat for the Treatment of COVID-19. Open Forum Infect Dis. 2020;7(7):ofaa241.

44. Davoodi L, Abedi SM, Salehifar E, Alizadeh-Navaei R, Rouhanizadeh H, Khorasani G, et al. Febuxostat therapy in outpatients with suspected COVID-19: A clinical trial. Int J Clin Pract. 2020:e13600.

45. Deftereos SG, Giannopoulos G, Vrachatis DA, Siasos GD, Giotaki SG, Gargalianos P, et al. Effect of Colchicine vs Standard Care on Cardiac and Inflammatory Biomarkers and Clinical Outcomes in Patients Hospitalized With Coronavirus Disease 2019: The GRECCO-19 Randomized Clinical Trial. JAMA Netw Open. 2020;3(6):e2013136.

46. Cao Y, Wei J, Zou L, Jiang T, Wang G, Chen L, et al. Ruxolitinib in treatment of severe coronavirus disease 2019 (COVID-19): A multicenter, single-blind, randomized controlled trial. J Allergy Clin Immunol. 2020;146(1):137-46.e3.

\section{Supplementary Files}

This is a list of supplementary files associated with this preprint. Click to download.

- SupplementaryFileFinal.docx 